Supplementary Information for

\title{
Autoxidized Hydroquinone Mimics the Optical Properties of Chromophoric Dissolved Organic Matter
}

\author{
Garrett McKay \\ Zachry Department of Civil \& Environmental Engineering \\ Texas A\&M University, College Station, TX \\ *gmckay@tamu.edu, 979.458.6540
}

11 pages

4 text sections

10 figures

\section{Section S 1 Analytical methods}

Spectral measurements were performed using both a Cary-100 UV-vis spectrophotometer (Agilent) and Aqualog spectrofluorometer (Horiba). The Cary-100 was employed for absorbance only, with either a 1 or $10 \mathrm{~cm}$ path length quartz cuvette. The Aqualog was employed for combined absorbance/fluorescence measurements. Fluorescence spectra were collected between 250-800 nm (in $2 \mathrm{~nm}$ increments) at varying excitation wavelengths $(240-800 \mathrm{~nm}$, in $5 \mathrm{~nm}$ increments). Fluorescence data were blank subtracted, corrected for inner filter effects, and normalized to Raman scatter unit area at $350 \mathrm{~nm}$ excitation. Apparent fluorescence quantum yields were calculated by employing quinine sulfate in $0.1 \mathrm{~N} \mathrm{H}_{2} \mathrm{SO}_{4}$ as a fluorescence reference standard $\left(\Phi_{f}\right.$ $=0.51)^{1}$ according to a previously described method. ${ }^{2} \mathrm{pH}$ was measured with a Thermo Scientific Orion Veristar $\mathrm{pH}$ meter and a combination $\mathrm{pH}$ microelectrode (Mettler-Toledo) following a threepoint calibration. Autoxidized hydroquione was further characterized by HPLC (Ultimate 3000, Thermo) equipped with diode array and fluorescence detectors. Samples were analzyed under an isocratic mobile phase containing $25 \%$ acetonitrile and $75 \%$ ammonium acetate. The column was a Supelco Ascentis RP-Amide column $(15 \mathrm{cmx} 4.6 \mathrm{~mm}, 5 \mu \mathrm{m})$. 


\section{Section $\mathbf{S}$ Calculation of average emission wavelength.}

The intensity-weighted average emision wavelength $\left(\lambda_{e m}^{a v g}\right)$ was calcaulted according to the following equation:

$$
\lambda_{e m}^{a v g}=\frac{\sum_{\lambda_{e m}} F_{\lambda_{e m}} \lambda_{e m}}{\sum_{\lambda_{e m}} F_{\lambda_{e m}}}
$$

where $F_{\lambda_{e m}}$ is the fluorescence intensity at emission wavelength $\lambda_{e m}$.

\section{Section $S 3$ Formation of autoxidized hydroquinone optical properties}

Spectral changes in buffered hydroquinone solutions occurred slowly, consistent with prior literature. ${ }^{3,4}$ Figure Figure $\mathrm{S} 1$ shows the time evolution of $2 \mathrm{mM}$ hydroquinone autoxidized over a period of 2 weeks.

Control experiments were performed to evaluate the influence of solution sterlization and deaeration on the evolution of autoxidized hydroquinone optical properties (Figure S 2). A $2 \mathrm{mM}$ solution of hydroquinone in $\mathrm{pH} 7,10 \mathrm{mM}$ phosphate buffer was filtered through $0.2 \mu \mathrm{m}$ nylon syringe filters. An aliquot of the filtered solution was treated with $0.05 \%$ sodium azide. Another aliquot was sparged with industrial grade $\mathrm{N}_{2}$ for $\sim 30 \mathrm{~min}$. The formation of visible absorbance and fluorescence signals occur more slowly in $\mathrm{N}_{2}$-sparged hydroquinone compared to air-saturated solutions, but is not abated altogether, potentially because of trace levels of $\mathrm{O}_{2}$ remaining in solution after $\mathrm{N}_{2}$-sparging. ${ }^{5}$ Evidence of chemical reaction (bubbles, color change) was apparent upon addition of $0.05 \%$ sodium azide to $2 \mathrm{mM}$ hydroquinone. Thus, azide is not an appropriate way to sterilize solutions. Apparently, azide reaction forms some products that give related spectral properties to hydroquinone autoxidized over longer periods.

Autoxidized hydroquione was further characterized by HPLC (Ultimate 3000, Thermo) equipped with diode array and fluorescence detectors. Chromatograms and associated spectra are shown in Figure S 3. Three Peaks were observed to elute over a $20 \mathrm{~min}$ run time, which could be identified as QHQ, hydroquinone, and p-benzoquinone based on their absorbance spectra These results are consistent with the idea that $\mathrm{p}$-benzoquinone is a main product of hydroquinone autoxidation.

\section{Section S 4. Equilibrium calculations of quinhydrone concentration}


In aerated solutions, hydroquinone $\left(\mathrm{H}_{2} \mathrm{Q}\right)$ oxidizes to form $\mathrm{p}$-benzoquinone $(\mathrm{Q})$, which may further interact with un-oxidized hydroquinone to form quinhydrone (QHQ). These processes can be described quantiatively by the following equilibrium expressions where all $E^{0}$ values are vs. SHE at $\mathrm{pH} 7$.

$$
\begin{array}{lll}
\mathrm{Q}+2 \mathrm{H}^{+}+2 \mathrm{e}^{-}=\mathrm{H}_{2} \mathrm{Q} & E^{0} \mathrm{~S}=0.643 \mathrm{~V} & \text { eq. } \mathrm{S} 2^{6} \\
\mathrm{H}_{2} \mathrm{Q}+\mathrm{Q}=\mathrm{QHQ} & K_{\mathrm{S} 3} & \text { eq. } \mathrm{S} 3
\end{array}
$$

It is possible to derive a quantiative expression relating $\left[\mathrm{H}_{2} \mathrm{Q}\right]$ to $[\mathrm{QHQ}]$ by first considering the half reactions for reduction of oxygen and the one-electron reduction of of Q and QHQ.

$$
\begin{array}{lll}
\mathrm{O}_{2}+2 \mathrm{H}^{+}+2 \mathrm{e}^{-}=1 / 2 \mathrm{H}_{2} \mathrm{O} & E_{\mathrm{S} 4}^{0}=1.268-(0.059)(7) \mathrm{V}=0.855 \mathrm{~V} & \text { eq. } \mathrm{S}^{7} \\
\mathrm{Q}+\mathrm{e}^{-}=\mathrm{Q}^{-} & E_{\mathrm{S} 5}^{0}=0.099 \mathrm{~V} & \text { eq. } \mathrm{S}^{6} \\
\mathrm{QHQ}+\mathrm{e}^{-}=\mathrm{Q}^{-}+\mathrm{H}_{2} \mathrm{Q} & E_{\mathrm{S} 6}^{0}=U_{\text {st }}-0.1984 \times \mathrm{pH} \times(273.15+T) & \text { eq. } \mathrm{S}^{8}
\end{array}
$$

where in eq. S6 $U_{\text {st }}$ is the standard redox potential at temperature $T\left(699.7 \mathrm{mV}\right.$ at $\left.25{ }^{\circ} \mathrm{C}\right) .{ }^{8}$ Thus, $E_{\mathrm{S} 6}^{0}=699.7 \mathrm{mV}-0.1984 \times 7 \times 298.15=285.6 \mathrm{mV}^{6}{ }^{6}$

Combining eq. S6 and eq. S5 yields a potential of $-0.187 \mathrm{~V}$ for eq. S3, which, upon employing the Nernst equation $\left(\ln K_{\mathrm{eq}}=n F E^{0}{ }_{\text {red }} / R T\right)$ yields $\ln K_{\mathrm{S} 3}=-7.268$. Combining eq. S2 and S4 yields

$$
\mathrm{H}_{2} \mathrm{Q}+\mathrm{O}_{2}=\mathrm{Q}+1 / 2 \mathrm{H}_{2} \mathrm{O} \quad E_{\mathrm{S} 7}^{0}=E_{\mathrm{S} 4}^{0}-E_{\mathrm{S} 2}^{0}=0.212 \mathrm{~V} \quad \text { eq. } \mathrm{S} 7
$$

Considering the above results it is now possible to obtain an expression relating [ $\left.\mathrm{H}_{2} \mathrm{Q}\right]$ to $[\mathrm{QHQ}]$. Combining eqs. $\mathrm{S} 3$ and $\mathrm{S} 7$ yields

$$
2 \mathrm{H}_{2} \mathrm{Q}+\mathrm{O}_{2}=\mathrm{QHQ}+1 / 2 \mathrm{H}_{2} \mathrm{O} \quad K_{\mathrm{S} 8}=K_{\mathrm{S} 3} K_{\mathrm{S} 7}
$$

$K_{\mathrm{S} 3}$ is known $\left(6.98 \times 10^{-4}\right)$ and $K_{\mathrm{S} 7}$ can be calculated from $E^{0} \mathrm{~S} 7$ and the Nernst equation $\left(K_{\mathrm{S} 7}=\right.$ $1.48 \times 10^{7}$ ), yielding $K_{\mathrm{S} 8}=1.03 \times 10^{4}$. Therefore, [QHQ] can be expressed as a function of $\left[\mathrm{H}_{2} \mathrm{Q}\right]$,

$$
\begin{array}{ll}
K_{\mathrm{S} 8}=[\mathrm{QHQ}] /\left(\left[\mathrm{H}_{2} \mathrm{Q}\right]^{2}\left[\mathrm{O}_{2}\right]\right) & \text { eq. } \mathrm{S} 9 \\
{[\mathrm{QHQ}]=K_{\mathrm{S} 8}\left[\mathrm{H}_{2} \mathrm{Q}\right]^{2}\left[\mathrm{O}_{2}\right]} & \text { eq. } \mathrm{S} 10
\end{array}
$$

Substituting $\left[\mathrm{H}_{2} \mathrm{Q}\right]=60 \mu \mathrm{M}$ and $\left[\mathrm{O}_{2}\right]=250 \mu \mathrm{M}$ yields $[\mathrm{QHQ}]=9.31 \times 10^{-8} \mathrm{M}$. Therefore, for intermolecular quinhydrone complexes, a low fraction of $\mathrm{H}_{2} \mathrm{Q}$ exists as QHQ $(0.016 \%)$. For $2 \mathrm{mM}$ autoxidized hydroquinone, this fraction is higher $(10.3 \mu \mathrm{M}$ or $0.517 \% \mathrm{QHQ})$, which is anticipated given that $[\mathrm{QHQ}]$ depends on $\left[\mathrm{H}_{2} \mathrm{Q}\right]^{2}$ in eq. $\mathrm{S} 10$. This result is consistent with previous literature stating that, in aqueous solution, quinhydrones are largely dissociated into quinone and hydroquinone ( $<1 \%$ quinhydrone $){ }^{8}$ 

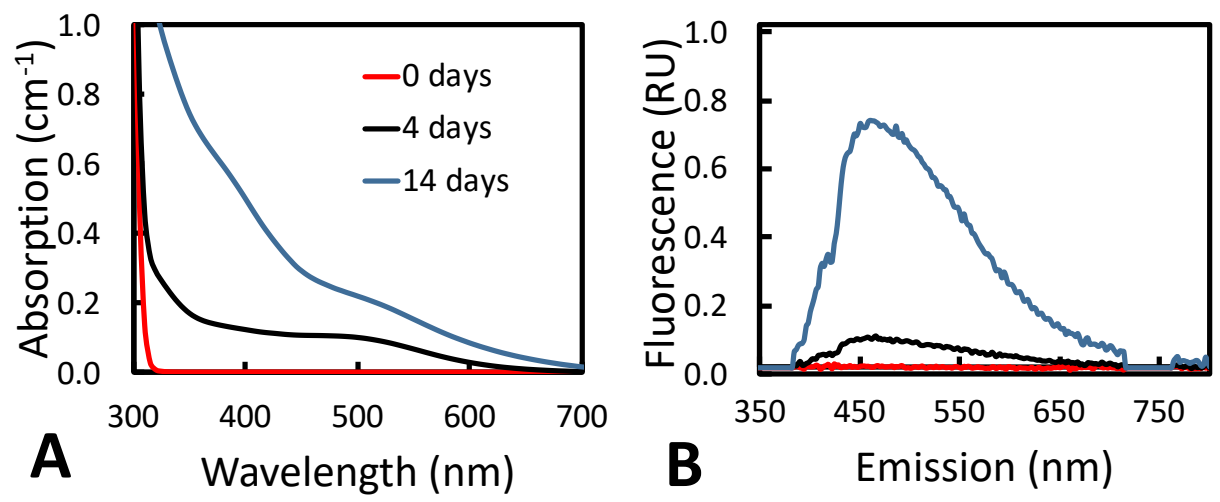

Figure S 1. Time evolution of absorbance (A) and fluorescence (B) spectra of $0.2 \mu \mathrm{m}$ filtered 2 $\mathrm{mM}$ autoxidized hydroquinone in $\mathrm{pH} \mathrm{7,10} \mathrm{mM}$ phosphate buffer. Emission spectra in $\mathbf{B}$ are at a $370 \mathrm{~nm}$ excitation wavelength.
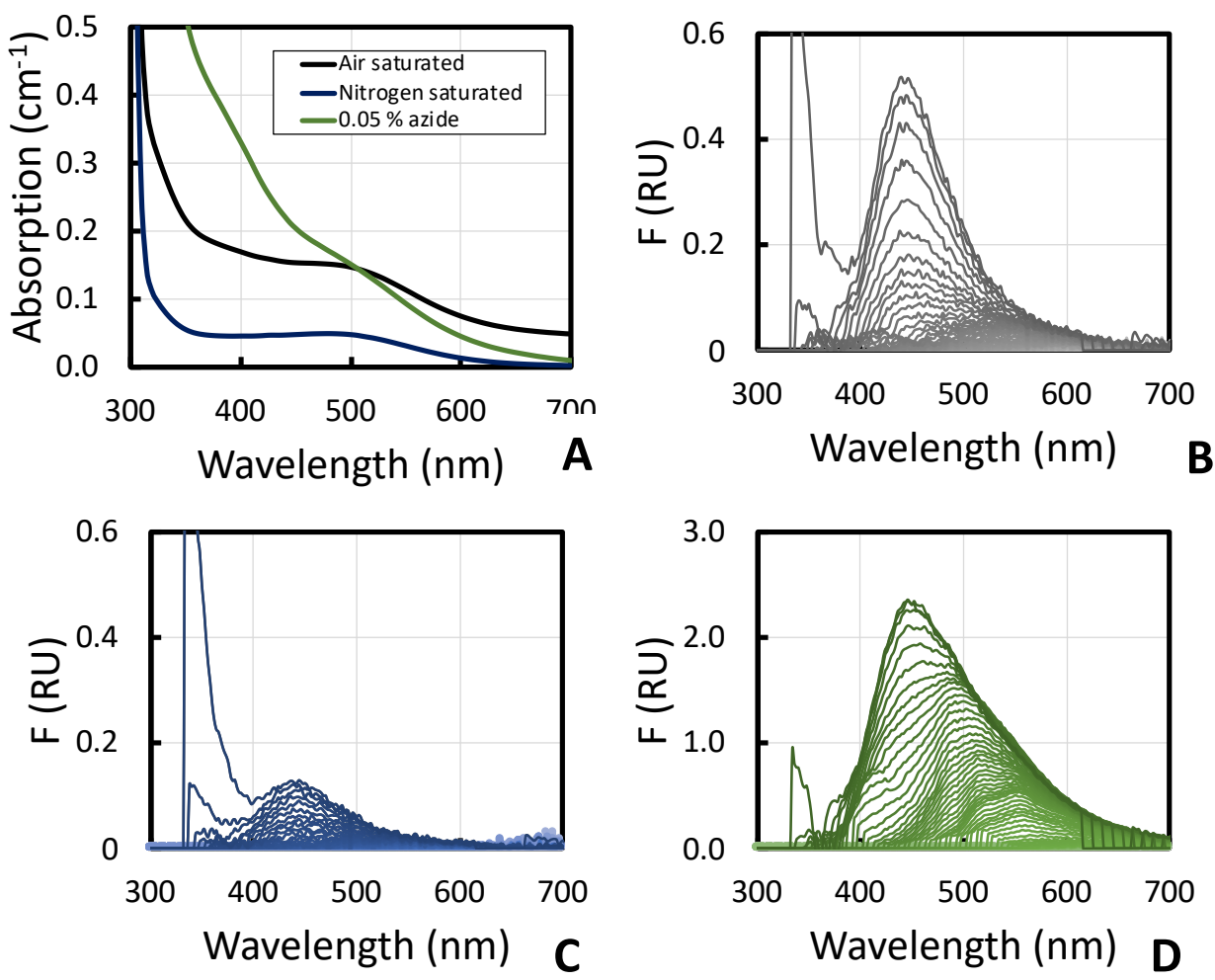

Figure S 2. Spectra of $0.2 \mu \mathrm{m}$ filtered $2 \mathrm{mM}$ hydroquinone in $10 \mathrm{mM}, \mathrm{pH} 7$ phosphate buffer after four days. (A) Comparison of absorbance spectra between air-saturated, nitrogen-saturated solutions, and $0.05 \% \mathrm{~m} / \mathrm{m}$ sodium azide solutions. (B-D) Fluorescence spectra of air-saturated (B), nitrogen-saturated $(\mathbf{C})$, and $0.05 \% \mathrm{~m} / \mathrm{m}$ sodium azide solutions $(\mathbf{D})$. 

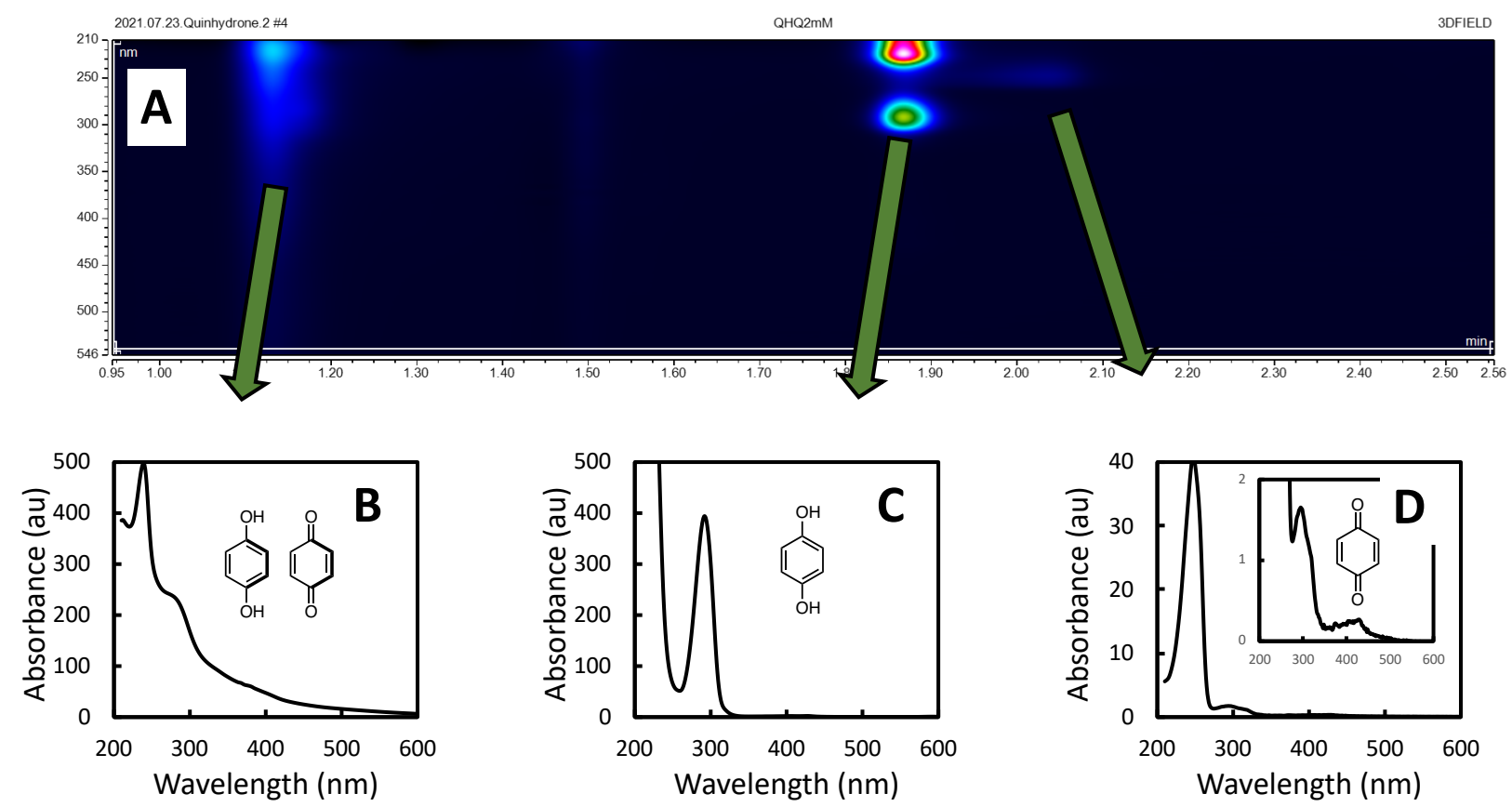

Figure S 3. (A) UV-vis spectra of $0.2 \mu \mathrm{m}$ filtered $2 \mathrm{mM}$ hydroquinone solution (aged for two weeks) during chromatographic separation by HPLC. (B-C) Associated spectra extracted from A indicated by green arrows, including quinhydrone $\left(B, R_{t} \sim 1.1 \mathrm{~min}\right)$, hydroquinone $\left(D, R_{t} \sim 1.85\right.$ $\min$ ), and $p$-benzoquinone ( $\mathbf{D}, \mathrm{R}_{\mathrm{t}} \sim 2 \mathrm{~min}$ ). Although only the first $\sim 2.5 \mathrm{~min}$ are shown here, the method run time was $20 \mathrm{~min}$, and no peaks were observed after the signal at $\sim 2 \mathrm{~min}$.

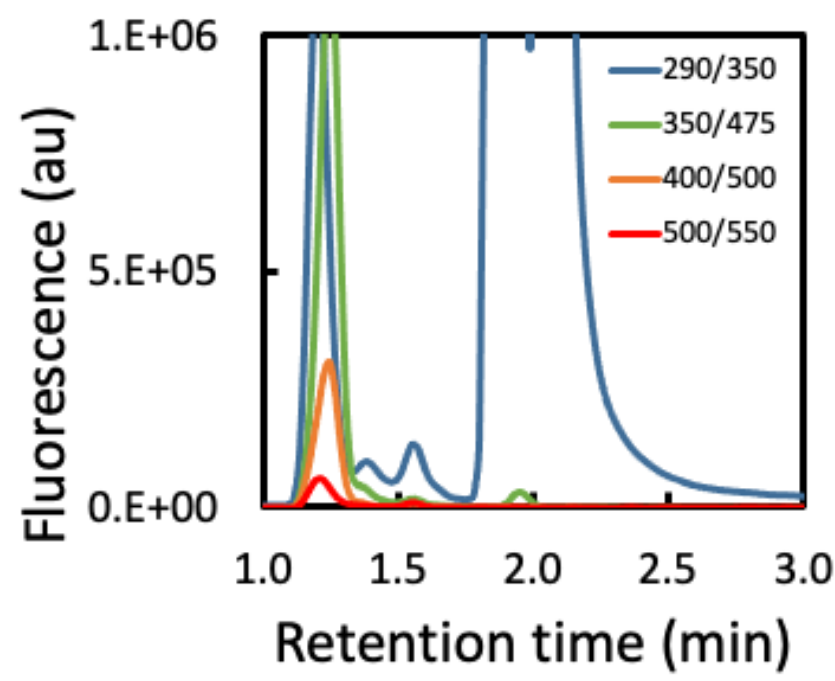

Figure S 4. Fluorescence intensity of $0.2 \mu \mathrm{m}$ filtered $2 \mathrm{mM}$ hydroquinone solution (aged for two weeks) during chromatographic separation by HPLC. Legend corresponds to the excitation/emission wavelength pair in $\mathrm{nm}$. Peak positions correspond to assignments in Figure $\mathrm{S}$ 3. Fluorescence of $2 \mathrm{mM}$ hydroquinone at $290 \mathrm{~nm}$ excitation saturates the detector, leading to the large peak width. 

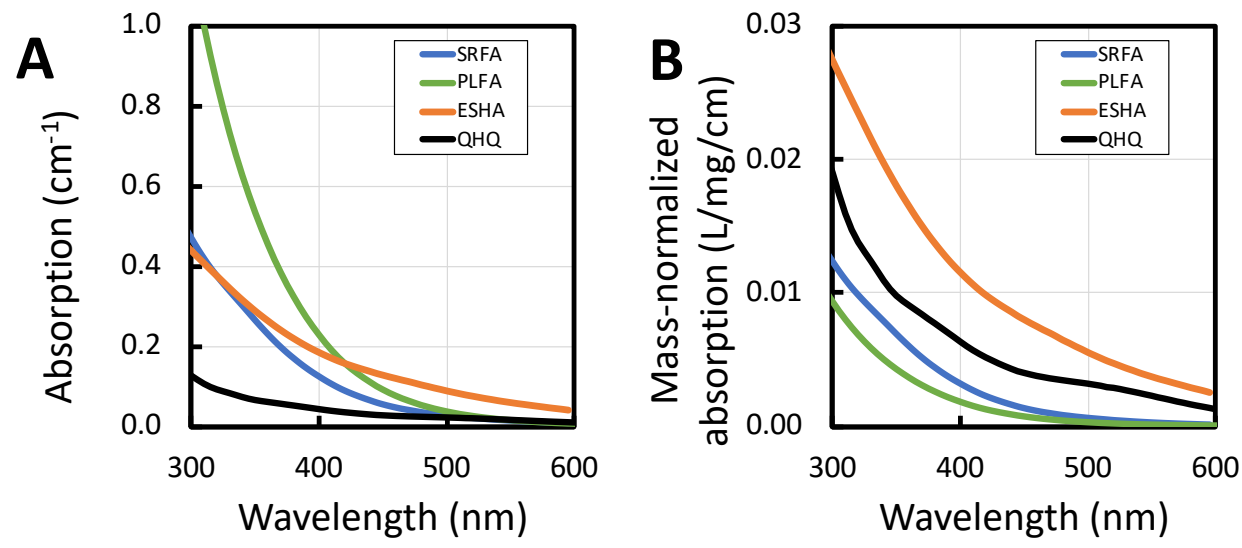

Figure S 5. Absorption (A) and mass-normalized absorption spectra (B) for Suwannee River fulvic acid (38 mg/L), Pony Lake fulvic acid (PLFA, $125 \mathrm{mg} / \mathrm{L})$, Elliot Soil humic acid (16 mg/L), and unfiltered autoxidized $60 \mu \mathrm{M}$ hydroquinone in $\mathrm{pH} 7$ phosphate buffer (QHQ). For QHQ, the initial concentration of hydroquinone in $\mathrm{mg} / \mathrm{L}$ was used for the normalization.
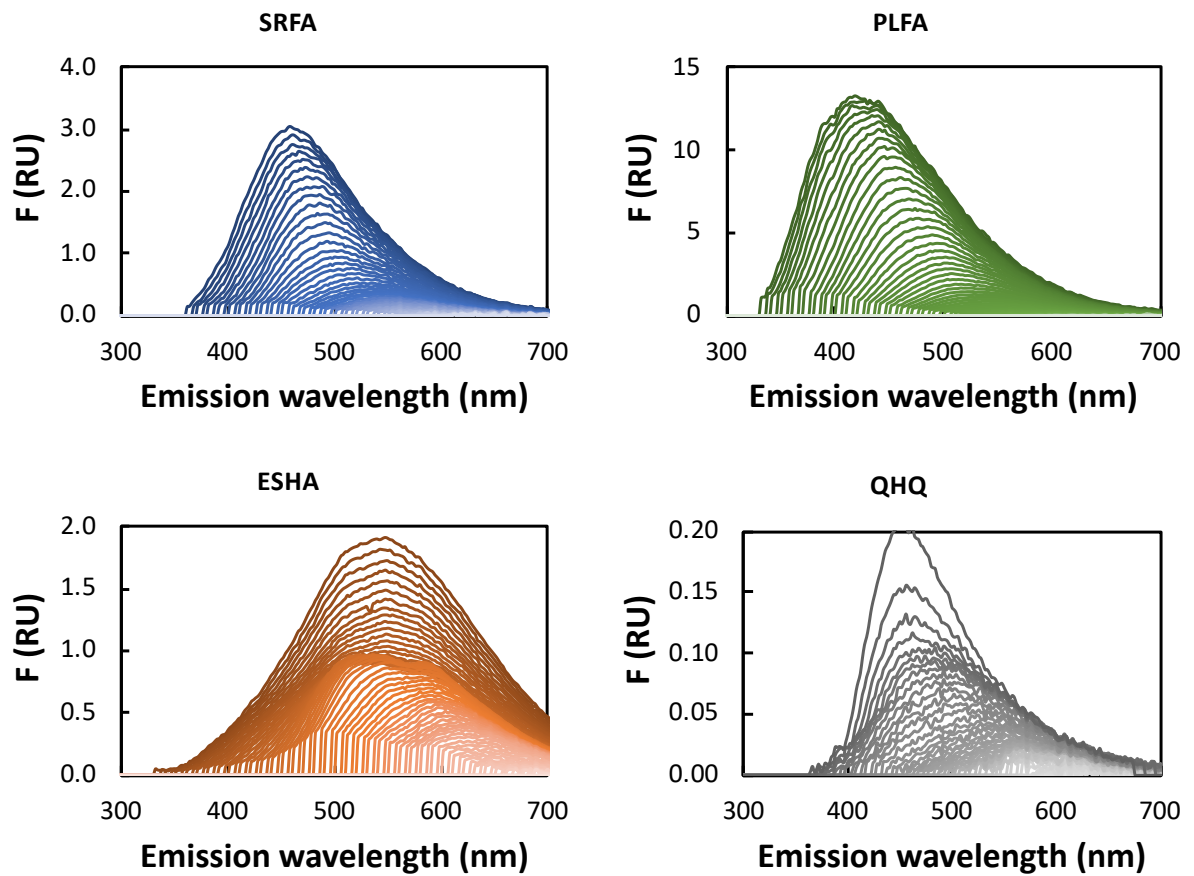

Figure S 6. Fluorescence emission spectra of Suwannee River fulvic acid (38 mg/L), Pony Lake fulvic acid (PLFA, $125 \mathrm{mg} / \mathrm{L})$, Elliot Soil humic acid $(16 \mathrm{mg} / \mathrm{L})$ and unfiltered autoxidized hydroquinone $(60 \mu \mathrm{M})$ in $\mathrm{pH} 7,10 \mathrm{mM}$ phosphate buffer. Emission spectra are shown from 350 to $600 \mathrm{~nm}$ excitation in $5 \mathrm{~nm}$ increments. 
Table S 1. Spectral slope values $\left(\mathrm{S}_{300-600}, \mathrm{~nm}^{-1}\right)$ for DOM isolates and autoxidized hydroquinone $(60 \mu \mathrm{M}, \mathrm{pH} 7$ phosphate buffer) as a function of $\mathrm{pH}$.

\begin{tabular}{|c|c|c|c|c|}
\hline & SRFA & PLFA & ESHA & QHQ \\
\hline pH 4 & 0.0175 & 0.0185 & 0.00740 & 0.00888 \\
\hline pH 7 & 0.0165 & 0.0178 & 0.00721 & 0.00794 \\
\hline pH 10 & 0.0158 & 0.0173 & 0.00699 & 0.00712 \\
\hline
\end{tabular}

SRFA

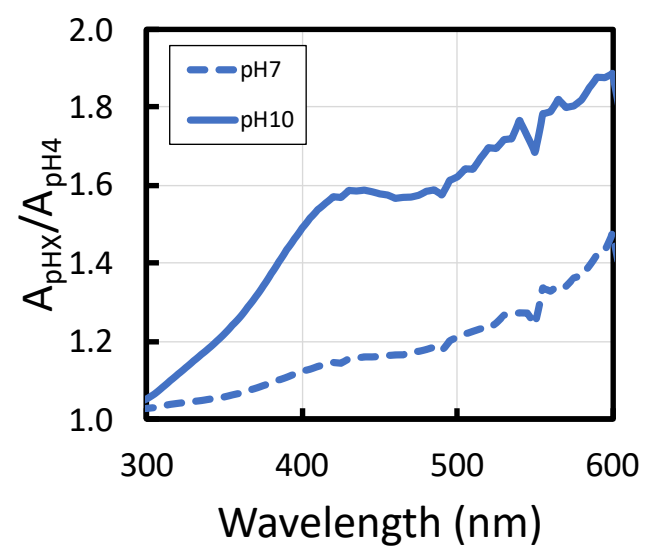

ESHA

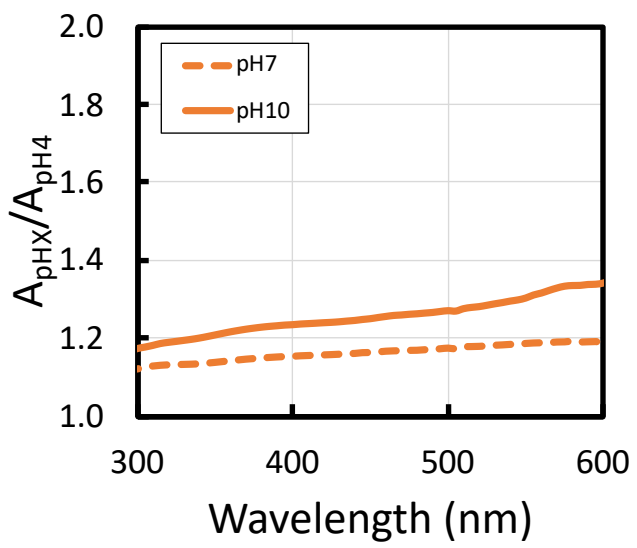

PLFA

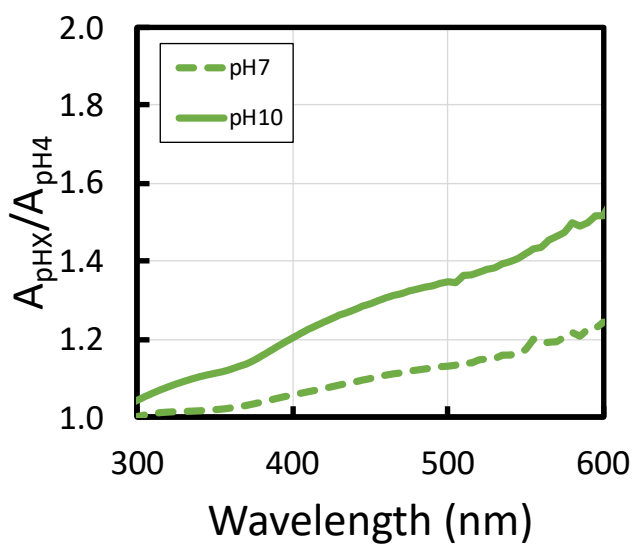

QHQ

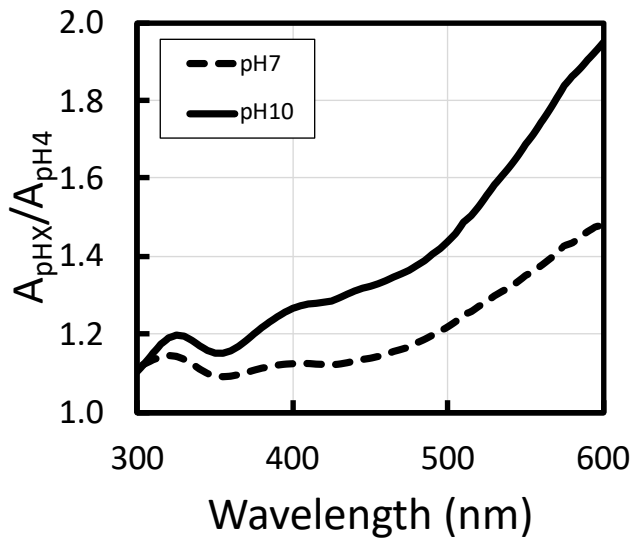

Figure S 7. Fractional absorbance enhancement as a function of $\mathrm{pH}$ relative to $\mathrm{pH} 4\left(\mathrm{~A}_{\mathrm{pHX}} / \mathrm{A}_{\mathrm{pH} 4}\right)$ for Suwannee River fulvic acid (SRFA), Pony Lake fulvic acid (PLFA), Elliot Soil humic acid (ESHA), and unfiltered autoxidized $60 \mu \mathrm{M}$ hydroquinone in $\mathrm{pH} 7,10 \mathrm{mM}$ phosphate buffer (QHQ). 

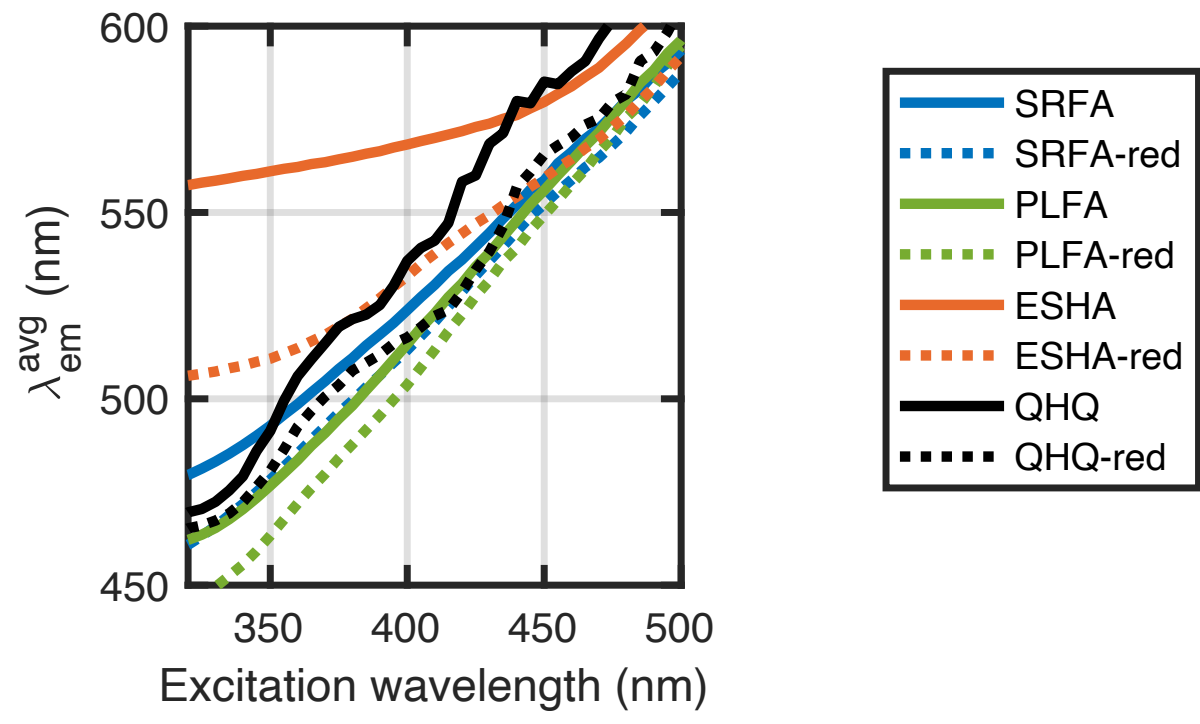

Figure S 8. Average emission wavelength as a function of excitation wavelength for native and reduced Suwannee River fulvic acid (SRFA), Pony Lake fulvic acid (PLFA), Elliot Soil humic acid (ESHA), and unfiltered autoxidized $60 \mu \mathrm{M}$ hydroquinone in $\mathrm{pH} \mathrm{7,10} \mathrm{mM} \mathrm{phosphate} \mathrm{buffer}$ (QHQ). Average emission spectra (eq. S2) for native samples are calculated at $\mathrm{pH} 7$, whereas values for borohydride reduced samples are at $\mathrm{pH} 10$. 

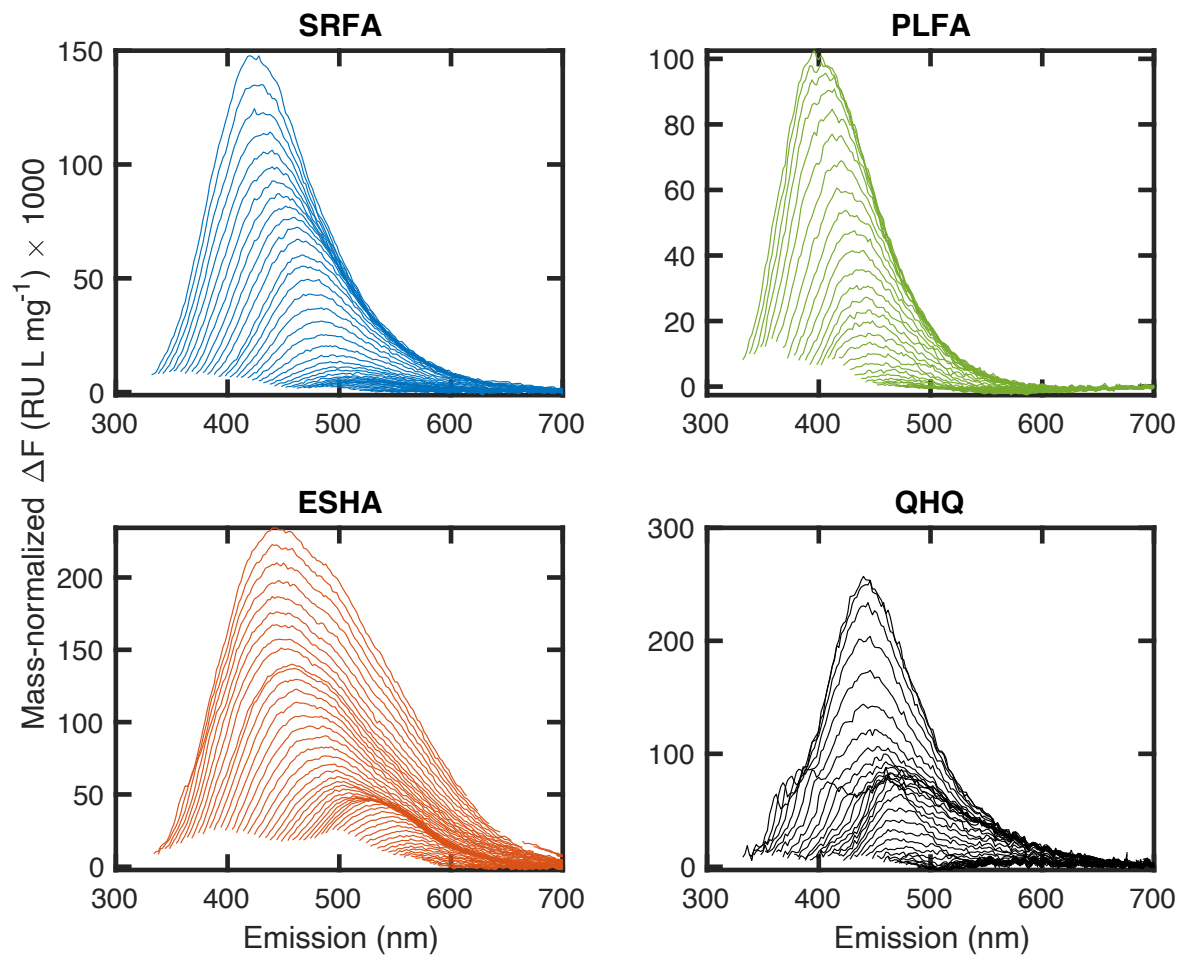

Figure S 9. Mass-normalized fluorescence difference spectra for borohydride reduced Suwannee River fulvic acid (SRFA), Pony Lake fulvic acid (PLFA), Elliot Soil humic acid (ESHA), and unfiltered aqueous autoxidized quinhydrone $(60 \mu \mathrm{M})$ in $\mathrm{pH} 7,10 \mathrm{mM}$ phosphate buffer. $\Delta \mathrm{F}=\mathrm{F}_{\text {red }}$ $-F_{\text {nat }}$ where $F_{\text {red }}$ is the borohydride reduced sample and $F_{\text {nat }}$ is the unreduced sample at $\mathrm{pH} 10$. Mass normalizatin for QHQ is with respect to the initial hydroquinone concentration in mg/L. Emission spectra are shown at excitation wavelengths ranging from 320 to $600 \mathrm{~nm}$. 

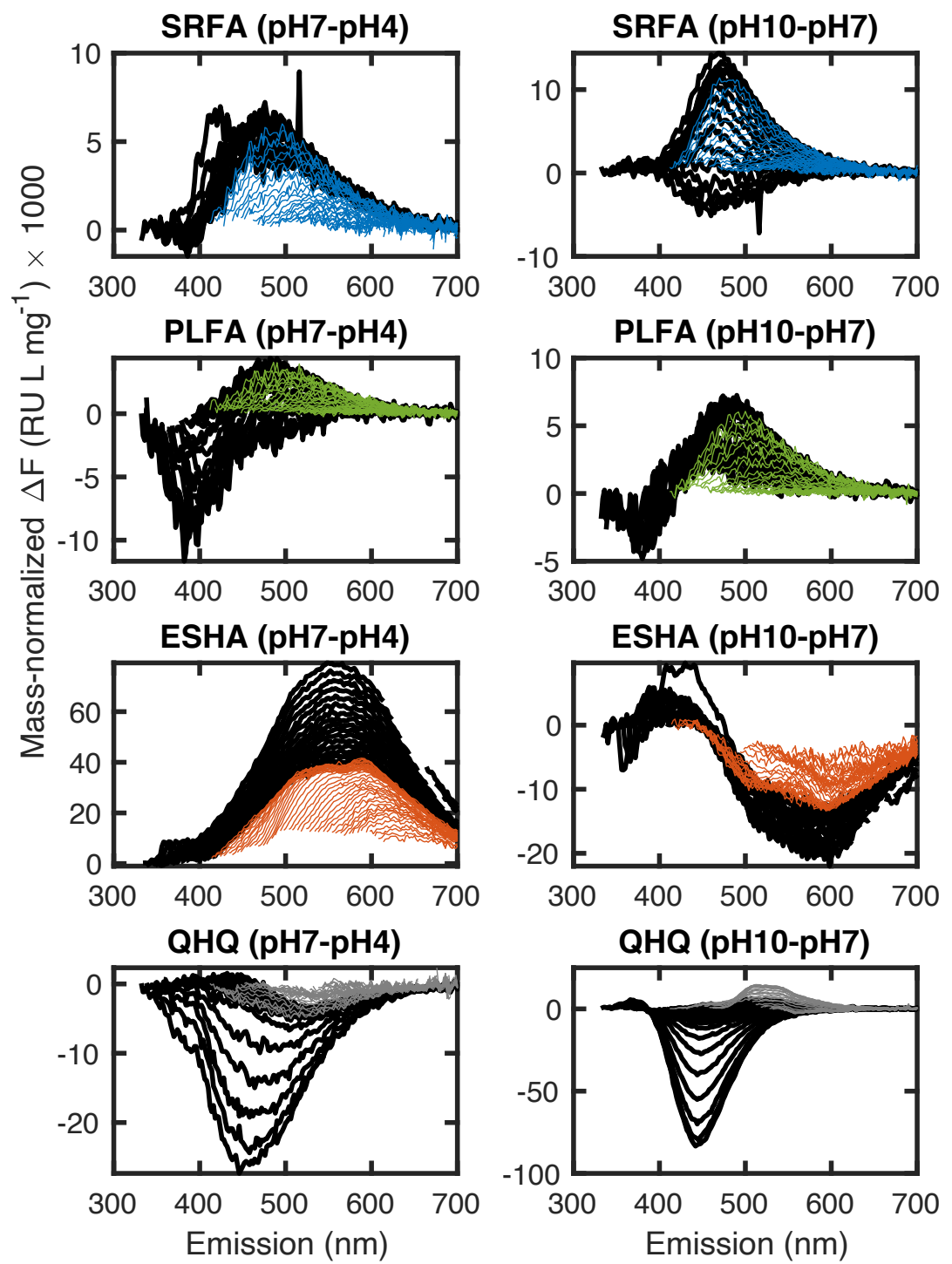

Figure S 10. Mass-normalized fluorescence difference spectra for $\mathrm{pH}$ titrated Suwannee River fulvic acid (SRFA), Pony Lake fulvic acid (PLFA), Elliot Soil humic acid (ESHA), and unfiltered aqueous autoxidized quinhydrone $(60 \mu \mathrm{M})$ in $\mathrm{pH} 7,10 \mathrm{mM}$ phosphate buffer. $\Delta \mathrm{F}$ is between either $\mathrm{pH} 7-4$ or $\mathrm{pH} 19-4$ and is defined in the figure title. Mass normalizatin for QHQ is with respect to the initial hydroquinone concentration in $\mathrm{mg} / \mathrm{L}$. Bold, black lines represent spectra measured at an excitation wavelength between 320 and $400 \mathrm{~nm}$. Colored lines represent spectra measured at an excitation wavelength between 405 and $600 \mathrm{~nm}$. 


\section{References}

1. Velapoldi, R. A.; Mieleaz, K. D. Standard Reference Materials: A Fluorescence Standard Reference Material; National Institute of Standards and Technology: Gaithersburg, MD, 1980.

2. McKay, G.; Korak, J. A.; Erickson, P. R.; Latch, D. E.; McNeill, K.; Rosario-Ortiz, F. L., The Case against Charge Transfer Interactions in Dissolved Organic Matter Photophysics. Environmental Science \& Technology 2018, 52, (2), 406-414.

3. Tentscher, P. R.; Escher, B. I.; Schlichting, R.; König, M.; Bramaz, N.; Schirmer, K.; von Gunten, U., Toxic Effects of Substituted P-Benzoquinones and Hydroquinones in in Vitro Bioassays Are Altered by Reactions with the Cell Assay Medium. Water research 2021, 117415.

4. Ariese, F.; van Assema, S.; Gooijer, C.; Bruccoleri, A. G.; Langford, C. H., Comparison of Laurentian Fulvic Acid Luminescence with That of the Hydroquinone/Quinone Model System: Evidence from Low Temperature Fluorescence Studies and Epr Spectroscopy. Aquatic Sciences 2004, 66, (1), 86-94.

5. Butler, I. B.; Schoonen, M.; Rickard, D. T., Removal of Dissolved-Oxygen from Water: A Comparison of Four Common Techniques. Talanta 1994, 41, (2), 211-215.

6. Huynh, M. T.; Anson, C. W.; Cavell, A. C.; Stahl, S. S.; Hammes-Schiffer, S., Quinone 1 E- and $2 \mathrm{E}-12 \mathrm{H}+$ Reduction Potentials: Identification and Analysis of Deviations from Systematic Scaling Relationships. Journal of the American Chemical Society 2016, 138, (49), 15903-15910.

7. Brezonik, P. L.; Arnold, W. A., Water Chemistry: An Introduction to the Chemistry of Natural and Engineered Systems. Oxford University Press, New York, New York, 2011.

8. $\quad$ Regeimbal, J.; Gleiter, S.; Trumpower, B. L.; Yu, C.-A.; Diwakar, M.; Ballou, D. P.; Bardwell, J. C. A., Disulfide Bond Formation Involves a Quinhydrone-Type Charge-Transfer Complex. Proceedings of the National Academy of Sciences 2003, 100, (24), 13779-13784. 